$\begin{array}{ll} & \text { Etnográfica } \\ \text { etnográfica } & \text { Revista do Centro em Rede de Investigação em }\end{array}$

Antropologia

vol. $12(1) \mid 2008$

Vol. $12(1)$

\title{
Nélia Dias, La mesure des sens: les anthropologues et le corps humain au xix éme siècle
}

\section{Luís Quintais}

\section{OpenEdition \\ Journals}

\section{Edição electrónica}

URL: https://journals.openedition.org/etnografica/1695

DOI: 10.4000/etnografica.1695

ISSN: 2182-2891

\section{Editora}

Centro em Rede de Investigação em Antropologia

\section{Edição impressa}

Data de publição: 1 mai 2008

Paginação: 269-272

ISSN: 0873-6561

\section{Refêrencia eletrónica}

Luís Quintais, «Nélia Dias, La mesure des sens: les anthropologues et le corps humain au xixéme siècle», Etnográfica [Online], vol. 12 (1) | 2008, posto online no dia 20 junho 2012, consultado o 12 fevereiro 2022. URL: http://journals.openedition.org/etnografica/1695 ; DOl: https://doi.org/10.4000/ etnografica. 1695

Etnográfica is licensed under a Creative Commons Attribution-NonCommercial 4.0 International License. 
João Leal

ANTROPOLOGIA EM PORTUGAL: MESTRES, PERCURSOS, TRADIÇÕES

Lisboa, Livros Horizonte, 2006, 215 páginas.

Na sequência de Etnografias Portuguesas (2000), João Leal afirma-se neste livro como o grande estudioso contemporâneo sobre a história da antropologia portuguesa desde os finais do século XIX até ao presente.

O livro (organizado a partir de artigos publicados anteriormente, quer como textos avulsos quer como introduções e prefácios a reedições de obras dos etnógrafos dos finais do século XIX e início do XX) retoma debates sobre os vários autores e seus objectos de estudo, com as temáticas e metodologias específicas do percurso da disciplina. Se em Etnografias Portuguesas o autor traça o quadro cronológico da história da etnografia portuguesa, desde os finais do século XIX até aos anos 70 do século XX, juntando temas ligados à própria ideia de "evolução" da disciplina, nesta segunda obra também três partes diferentes correspondem a três subtemáticas, nomeadamente "mestres", “percursos" e "transições".

O mote é dado na primeira parte que, retomando uma expressão de Jorge Dias no seu "Bosquejo histórico da Etnografia Portuguesa", se debruça sobre os grandes "mestres" - etnógrafos como Consigleri
Pedroso, Adolfo Coelho, Teófilo Braga e Leite de Vasconcellos - realçando facetas que, se bem que apontadas em $E P$, são agora desenvolvidas.

Por exemplo, o ensaio inicial sobre Consiglieri Pedroso começa com a contextualização histórica deste período (referido por Jorge Dias como "filológico-positivista”) como uma época decisiva na história da disciplina, que transforma o interesse romântico pela cultura popular num esforço sistematizado e com orientação científica.

O mesmo fio condutor é utilizado ao abordar as obras de outros dois "mestres" Adolfo Coelho e José Leite de Vasconcellos. Deste modo, nestes três ensaios, para além de resumir e analisar os temas estudados por cada uma destas figuras tutelares, Leal preocupa-se em contextualizar tais produções, quer em termos do quadro dos temas gerais privilegiados pela etnografia europeia da época, quer das influências teóricas subjacentes, que assim terão dirigido os trabalhos dos etnógrafos portugueses.

Leal salienta a abertura de A. Coelho aos estudos de terreno e às preocupações com a identidade e decadência nacional, ao mesmo tempo que aponta as influências do difusionismo e sublinha as dispersões teóricas presentes, tal como a mitologia comparada e o evolucionismo, e ainda o modo como este estudioso se debruçou sobre o tema da cultura popular e da educação, reflectindo 
sobre as várias facetas dos seus textos, tais como "A pedagogia do povo português".

Retoma assim a discussão do que ele considera temas essenciais na produção etnográfica portuguesa dos finais do século XIX e início do século XX - a literatura e mitologias populares e a preocupação com a identidade nacional e a etnogenia -, ideia que corrobora nas linhas escritas sobre Teófilo Braga.

Em relação a Leite de Vasconcellos, Leal passa em revista o seu percurso, marcado pelo que denomina "um vaivém entre a etnografia e a arqueologia”, que insere no quadro geral da proximidade entre as duas disciplinas na segunda metade do século XIX. Considerando Tradições Populares de Portugal como uma das "mais importantes recolhas de tradições populares da antropologia portuguesa oitocentista", analisa essa oscilação entre a etnografia e a arqueologia, referindo a criação do Museu Etnográfico Português e a fundação da revista $O$ Arqueólogo Português, que mostram, sobretudo a partir de 1895, o comprometimento de Leite de Vasconcellos com a arqueologia (quer no plano institucional, quer no plano científico), patente nos três volumes de Religiões da Lusitânia, que Leal considera a sua obra fundamental no domínio da arqueologia.

Traçando o percurso de Vasconcellos, Leal refere ainda como, no final dos anos 20 , as suas prioridades sofrem de novo uma reviravolta e a par de textos sobre arte popular surgem textos de etnografia comparativa, focando temas como os amuletos populares (signum solomonis, figa e a barba) e, finalmente, a publicação de Etnografia Portuguesa, que pretendia ser um compêndio de síntese etnográfica sobre a cultura popular portuguesa, intenção essa interrompida pela morte do autor.

Nesta conexão constante entre o passado e o presente, Leal enfatiza a figura dos Lusitanos e a importância que Leite de Vasconcellos dava à análise da cultura popular à luz desse fundo lusitano matricial da nação, um espaço cronológico delimitado entre a pré-história e a fundação da nacionalidade, em que a sucessão de povos teria moldado a cultura tradicional portuguesa (p. 69).

Leal liga ainda os textos sobre amuletos, signo saimão e figa às preocupações étnico-genealógicas do seu autor, como representantes do "projecto subjacente ao diálogo entre etnografia e arqueologia em L. de Vasconcellos", salientando como a etnografia portuguesa acabou por assumir um declínio, em detrimento das preocupações mais interpretativas ligadas à exploração das raízes etnogenéticas da cultura portuguesa.

A respeito das preocupações folcloristas de L. de Vasconcellos no texto sobre a barba, e referindo outras figuras da etnografia portuguesa da "celebração do popular" - discípulos de L. V. como Luís Chaves, F. C. Pires de Lima, Cláudio Basto e Virgílio Correia demonstra como L. de Vasconcellos procede a um tratamento do tema de um prisma comparativo, utilizando a etnografia e a história. Ao propor a leitura destes três ensaios não apenas como documentos relevantes para o entendimento do percurso científico do seu autor e da antropologia da época, mas também como textos com elementos informativos e sugestões de análise interessantes (p. 77), Leal realça e relembra-nos a actualidade e pertinência destes textos de Vasconcellos.

Na segunda parte, intitulada "Percursos", a intenção é agrupar uma série de ensaios que exploram temáticas importantes no desenvolvimento da antropologia portuguesa, quer problematizando a relação entre identidade nacional e antropologia, quer analisando temas ligados ao que Leal denomina "etnografia espontânea".

Assim, após uma primeira incursão nas teorias evolucionistas sobre a família e os ecos do debate das mesmas (nomeadamente nos textos de C. Pedroso já referidos), Leal menciona ainda como os textos de T. Braga e de Oliveira Martins espelham a influência de Maine e de Foustel de Colanges. 
No capítulo "Imagens contrastadas do povo", Leal mostra como o discurso afirmativo, de confiança romântica na nação, e um contorno pessimista sobre a decadência nacional, sobretudo com Adolfo Coelho e Rocha Peixoto, perduraram na segunda metade do século XIX, o primeiro ligado a uma imagem positiva e romântica da cultura popular, o segundo a uma imagem negativizada do povo. Para Leal, tais discursos mostram como a antropologia portuguesa da época oscilou entre os imperativos românticos de fornecer uma identidade à nação e a tendência inversa, de olhar a sua desconstrução e declínio.

É ainda sob este signo de influências teóricas e preocupações, que se balanceiam entre a defesa da identidade nacional e a sistematização da diversidade e riqueza cultural do país, que o ensaio seguinte se centra. Reflectindo sobre as discrepâncias entre duas tradições antropológicas no mundo ocidental - a "antropologia de construção de império" dos países desenvolvidos da Europa e da América e a "antropologia de construção da nação" dos países periféricos da Europa - Leal lembra que, em Portugal, apesar da existência de um império colonial, a antropologia se desenvolveu a partir do segundo modelo, centrado sobre a problemática da identidade nacional. As razões para tal prendem-se com a fraqueza do colonialismo português e o modo como as questões relacionadas com a identidade nacional ocuparam a vida intelectual portuguesa nos últimos 150 anos, nomeadamente o que Leal denomina, a partir de Eduardo Lourenço, "a fragilidade ôntica da nação". A percepção de Portugal como país problemático teria levado “à necessidade de reforçar o discurso sobre a identidade nacional de raiz cívico-territorial (...), com argumentos etnogenealógicos susceptíveis de conferir maior espessura a uma existencia nacional fragilizada" (p. 113).
Leal analisa aqui, à semelhança do que faz em $E P$, os quatro períodos segundo ele determinantes na antropologia portuguesa entre 1870 e 1970 (1870-1880; 1890-1900: 1910-1920; 1930- 1970), mostrando como a cada um destes períodos corresponde uma linha de força, em que, no primeiro, Portugal é visto como produto de originalidades étnicas presentes na literatura e nas tradições populares; no segundo descobre-se a diversidade interna do país; e, no terceiro, a implantação da República e o optimismo sobre o destino nacional moldam uma etnografia nacionalista de carácter folclorizante estruturada em torno da arte popular. Por último, mostra como, no quarto momento, a figura de Jorge Dias e da sua equipa Margot Dias, Fernando Galhano, Ernesto Veiga de Oliveira e Benjamim Pereira- se impôs no panorama da antropologia portuguesa, através das monografias sobre comunidades do Norte, dos ensaios sobre a cultura popular e, sobretudo, em termos de uma "etnografia de urgência", no estudo da cultura material e das tecnologias tradicionais, animada pela preocupação em traçar um retrato da diversidade e riqueza cultural do país.

No final deste capítulo, a propósito do período a partir de 1890, em que a arte popular é recuperada pelos estudiosos, Leal menciona figuras esquecidas do campo da etnografia na sua ligação a esta área, como Joaquim Vasconcelos, Virgílio Correia e Ernesto de Sousa, salientando, no primeiro, o seu trabalho de nacionalização da arte popular ligado a uma noção de urgência de salvaguardar o que rapidamente se perderia; em Virgílio Correia, a sua perspectiva pastoral de encantamento com a arte pastoril e as indústrias caseiras; em Ernesto de Sousa, a sua forma de questionar o gosto do Estado Novo e o modo como desenvolveu a equação entre arte ingénua, primitivismo e modernismo, e tornou conhecidas figuras como Franklin e outros artistas populares. 
Leal termina esta secção de uma forma bastante criativa, imaginando como estes três personagens ficariam encantados se pudessem visitar as feiras de artesanato actuais e como Joaquim de Vasconcelos se entusiasmaria com o renascimento da estatuária de granito, Virgílio Correia com as miniaturas de Estremoz, das irmãs Flores, e Ernesto de Sousa conversaria com as netas de Rosa Ramalho e de Mistério.

$\mathrm{Na}$ terceira e derradeira parte do livro, "Transições", agrupam-se ensaios sobre a nova antropologia que surge em Portugal a partir da década de 60 , sobretudo com o aparecimento de olhares de fora, de antropólogos estrangeiros que trazem novas perspectivas e destronam a "articulação estruturante entre antropologia e identidade nacional". Assim, o tema da perspectiva pastoral versus contrapastoral surge a propósito de três grandes figuras da etnologia mais recente, a partir dos anos 50 do século XX, com Orlando Ribeiro, Jorge Dias e José Cutileiro. Embora salientando as diferenças entre eles- nomeadamente o facto de Orlando Ribeiro ser geógrafo humano e apaixonado pelo Sul e Jorge Dias ser antropólogo e encantado com o Norte Leal equaciona as perspectivas destes dois autores de uma visão pastoral do país e da vida das pessoas, uma espécie de idealismo cego em que apenas as vertentes positivas são salientadas. Ao contrário, o trabalho de José Cutileiro é nomeado por ter por trás uma visão contrapastoral, na medida em que se centra na luta de classes e poderes no Alentejo rural nos anos finais do regime salazarista e consegue uma aproximação realista a esta situação.

As premissas básicas que enformam este capítulo são continuadas no seguinte, em que se debatem as novas formas de fazer antropologia em Portugal que surgem a partir da década de 60 , com os primeiros esforços no sentido da criação de uma "anthropology of empire building”, os estudos de Jorge Dias entre os Macondes de Moçambique, a criação do curso de antropologia no ISCSPU e o projecto do Museu de Etnologia. Grande parte dessa inovação deve-se a antropólogos estrangeiros: Leal enfatiza o modo como os trabalhos de Collette Callier-Boisvert sobre as mulheres e a emigração na serra minhota, e os de Joyce Riegelhaupt sobre anticlericalismo na região saloia trouxeram uma lufada de ar fresco e um novo olhar sobre o país. Retoma também o estudo de Cutileiro que, apesar de português, contribuiu com a visão do funcionalismo britânico para a disciplina, dando conta de uma situação social marcada pela desigualdade e pelo conflito.

João Leal tem o dom de juntar níveis de análise e temáticas diferentes (autores, métodos, objectos, influências teóricas) e de dar uma elucidativa visão de conjunto do panorama da etnologia portuguesa nos períodos realmente relevantes para a construção da disciplina, entre os finais dos séculos XIX e XX, coincidentes com épocas de acelerada mudança histórica, política e social do país. A sua originalidade, para além de todo o trabalho de estudo das obras clássicas que está patente, prende-se com o modo como, de uma forma reflectida e crítica, Leal aponta como os primeiros antropólogos portugueses estabeleceram diálogos com as teorias antropológicas internacionais, conduzindo-nos através de um percurso que mostra as "pequenas guerras culturais" da construção da identidade nacional e da própria disciplina. Esta é, sem dúvida, uma obra de referência para qualquer estudioso da antropologia portuguesa, do modo como ela se moldou e simultaneamente influenciou um país em transformação, permitindo o alargamento de perspectivas e de âmbitos de análise de que a disciplina usufrui presentemente.

\section{Clara Saraiva}

Instituto de Investigação Científica Tropical e Universidade Nova de Lisboa 
Nélia Dias

LA MESURE DES SENS:

LES ANTHROPOLOGUES ET LE CORPS HUMAIN AU XIXÉME SIÈCLE

Paris, Aubier, 2004, 357 páginas.

O estudo de Nélia Dias, que pretendo aqui apresentar, sendo um trabalho lucidamente empírico, coloca-nos perante um problema teórico que me parece de extrema dificuldade e para o qual as respostas são quase sempre lacunares e insuficientes. De algum modo, este problema está subjacente a uma parte importante do pensamento social e político desde Thomas Hobbes, pelo menos. Trata-se de pensar as recursividades e analogias de natureza epistémica e política entre o corpo individual e o corpo colectivo. Ou, de outro modo, de que forma é que o conhecimento e práticas dos lugares do corpo se traduzem politicamente. Assim, não é por acaso que este transporte faz de Thomas Hobbes o "primeiro sociobiólogo", como reclama o filósofo cognitivista e darwiniano Daniel Dennett em Darwin's Dangerous Idea (1995: 453). Porque em Thomas Hobbes há um apelo a uma teoria naturalista acerca da moral e, concomitantemente, uma translação de sentido político que faz de uma sociedade o resultado de tal declinação naturalista. Esta pretensão é certamente um dos aspectos mais insistentes da modernidade: uma vontade política que assume que conhecer é poder ou, ainda, que aquilo que é - essa ordem factual em que se abastece o mundo e que cumpre a um estilo de pensamento e suas extensões exumar - regulará imperiosamente o deve, isto é, o modo de gerir indivíduos e colectivos de indivíduos. Tudo isto faz supor que a relação entre conhecimento e regulação é inegociável e que devemos deixar os modos de regulação da pólis nas mãos dos especialistas, dos sacerdotes do templo, isto é, dos sábios ou, se quisermos, de um certo tipo de sábios: os cientistas. São eles que sabem o que é, logo é através deles que devemos regular o que deve ser no plano ético-moral e no plano político.

Não resisto aqui a citar Thomas Hobbes e o seu Leviathan no original: "Reason is the pace; Encrease of Science, the way; and the Benefit of man-kind, the end" (1981 [1651], Parte I, cap. 5, pp. 21-22).

É tendo em conta esta tendência moderna que não nos abandonou ainda e que certamente não nos irá abandonar tão cedo (apesar dos seus acentos trágicos que a história do século XX, em particular, denuncia de forma impiedosamente ímpar), que o livro de Nélia Dias deverá ser lido, porque a investigadora mostra-nos um dos modos em que isto se desdobrou num determinado contexto cultural e científico do século XIX: a França da segunda metade desse século. Mostra-nos também como esta pulsão moderna não admitiria a ambiguidade da sua consagração metafórica - esse enlace analógico e impreciso entre corpo individual e corpo político - e que toda a ambiguidade teria de ser expurgada do sistema através de uma estratégia rigorosamente localizadora e especificadora. Como?

O livro é uma análise sincrónica de um domínio discursivo específico. Trata-se de mostrar como a segunda metade do século XIX assistiu a um denodado exame dos órgãos dos sentidos em que se impunha fundamentalmente realizar uma topobiologia dos sentidos. Estamos perante uma espacialização e hierarquização no corpo de uma ordem sensorial. Como explicita Nélia Dias, o exame dos sentidos e da hierarquia em que se fundam articula-se discursivamente com uma matriz de oposições politicamente significativas que demonstram, justamente, a recursividade entre corpo individual e corpo colectivo. Assim, a partição entre hemisférios esquerdo e direito do cérebro desdobrava-se numa assimetria de faculdades e atribuições: razão/instinto, 
cor azul/cor vermelha, homem/animal, civilizado/primitivo, homem/mulher. Dir-se-ia que estamos perante um episódio clássico em que a topobiologia faz supor ou traduz todo um conjunto de aproximações analógicas entre diversos domínios que vão da classificação sensorial à taxonomia racial e à estratificação social. O livro de Nélia Dias demonstra-nos a extrema capilaridade entre discursos científicos e políticos numa certa concepção de modernidade que, à partida, parece reclamar a autonomia de tais esferas. Daí que, metodologicamente, o universo de domínios discursivos relevantes seja vastíssimo: antropologia, fisiologia, psicologia, filosofia, medicina e literatura assumem aqui uma importância decisiva na produção do argumento. Mais uma vez estamos perante uma leitura impressiva da hibridez fundamental da modernidade. Algo que aproxima Nélia Dias de Bruno Latour (1997 [1991]) e, de modo muito específico (dado o alcance da sua análise e a natureza dos materiais em que tal análise se abastece), de Anne Harrington (1987).

Se este é o eixo maior de articulação em que o trabalho de Nélia Dias se define, paralelamente este trânsito entre a topobiologia e a representação do corpo social e político foi um projecto que solicitou todo um conjunto de estratégias e de reflexões epistemológicas que apaixonaram os especialistas da época. De outro modo, poder-se-ia dizer que esta cartografia de alguns dos veios, em que se abasteceram os discursos antropológicos oitocentistas sobre os sentidos, define também a perturbação que os atravessava: a perturbação por um certo "perspectivismo" ou consciência dele que se prende afinal com os "modos de ver" e sua radical alteridade; a perturbação face às diferenciais aquisições cognitivas que mecanismos anatomo-fisiológicos descritos como diferentes (e a diferença aqui poderia ser enunciada como do domínio do patológico ou teratológico) evidenciavam; a perturbação face à possibilidade de o conhecimento verdadeiro ser função de uma ordem sensorial que teria de ser precisada e defendida a todo o custo. Precisar e defender a epistemologia seria também, e concomitantemente, um modo de precisar e defender uma certa concepção de sociedade.

Estamos aqui perante um problema que se prende, evidentemente, com algumas das formulações de Michel Foucault. Aliás, $\mathrm{La}$ Mesure des Sens é uma hábil incursão em território foucauldiano. Aí, para lá da centralidade da noção de "discurso", impõem-se as noções de "anotomo-política do corpo humano" e de "biopolítica das populações" que Foucault irá articular no volume metodológico da sua História da Sexualidade, isto é, em A Vontade de Saber (1994 [1976]: 141-47). O conhecimento do corpo-máquina torna-se uma plataforma a partir da qual a ordem social e demográfica poderá ser cabalmente aferida. Ou seja, Nélia Dias mostra-nos não apenas as modalidades em que se desdobrava este conhecimento ou o conjunto de séries discursivas em que o mesmo se instalava, mas também a relação diagramática que estes conhecimentos ou séries estabeleciam estrategicamente uns com os outros para produzir uma configuração política - uma forma de "podersaber" (id.: 145) - acerca do corpo-espécie e suas derivas, que era assim espacializado e articulado de acordo com definições de identidade colectiva. Veja-se, a este propósito, o que Nélia Dias escreve acerca da constituição do Estado num capítulo que destaca a biopolítica das ordens sensoriais e sua tradução estatística e cartográfica (capítulo 9 de La Mesure des Sens: pp. 263-80).

O que está aqui em causa é o trânsito entre o corpo individual e o corpo político. Que tipo de efeitos e de metáforas regem a sua constituição mútua, num mundo onde as metáforas se encontram permanentemente sob suspeita?

A identificar alguns dos fluxos metafóricos na produção do corpo político, destacaria 
aqui o modo como Nélia Dias nos descreve as formas de representação do sistema nervoso e as suas continuidades e contiguidades com as formas de representação do sistema político. Socorrendo-se de Hyppolite Taine, escreve a autora de La Mesure des Sens:

A analogia entre sistema nervoso e sistema político está também presente em Taine. A descrição figurada que o filósofo dá do sistema nervoso, com os seus ministérios e os seus centros locais, é à imagem de uma burocracia centralizada, composta de uma "hierarquia de funcionários"; longe de ser uma "república de iguais", cada centro local detém uma certa autonomia, sendo dado que "o sistema de centros nervosos na medula e no encéfalo se assemelha ao sistema de poderes administrativos num Estado" (...). E adianta, a propósito de trinta e um centros espinais, que "são outras tantas prefeituras subordinadas a um ministério que assentam na medula alongada. Cada um destes centros tem o seu departamento ou território próprio; nele recebe as informações pelos seus nervos sensíveis; aí dá as ordens pelos seus nervos motores". O primeiro ministério "ocupa toda a medula alongada, isto é o bolbo, a protuberância e talvez os começos dos pedúnculos cerebrais. (...) Há vários andares sobrepostos, repartições sensíveis de diversas espécies, repartições motoras, comunicações que ligam estas repartições entre elas e que se ligam elas próprias a superiores hierárquicos, seja para transmitirem informações, seja para receberem ordens. Segue-se em seguida e sobre a medula, o ministério supremo. (...) Além das informações que lhe transmite a medula alongada, ele recebe as instruções que trazem os dois primeiros pares de nervos cranianos, olfativos e ópticos; deste modo todas as impressões sensíveis se reúnem nestas repartições, e, além disso, através da medula alongada, envia impulsos para todos os nervos motores. Sobre ele, na cobertura cerebral, instala-se o soberano". (...) Encontramos em Taine todo um sistema de correspondências - o soberano/a cobertura cerebral, o primeiro ministério/a medula alongada, os departamentos e prefeituras/os centros espinais - o que não é fortuito quando conhecemos a admiração que votava à monarquia inglesa e a sua hostilidade à democracia plebiscitária (pp. 286-7).

Um dos modos de captarmos esta capilaridade entre corpo individual e corpo colectivo ou de percebermos como é que a anatomo-política do corpo humano e a biopolítica das populações se constituem mutuamente, nada melhor do que seguir o percurso das metáforas, parece querer dizer-nos Nélia Dias, numa estratégia que a aproxima de Hans Blumenberg (1997). O corpo é não somente uma cidade, neste contexto. Ele é, e à luz do conhecimento produzido acerca do sistema nervoso, uma cidade que comunica - algo que a analogia entre o sistema nervoso e o telégrafo parece acentuar (ver pp. 288-90). A civilização faz supor assim que a cidade passou a habitar o corpo e que a transitividade controlada entre a tópica do corpo e a tópica da cidade se tornou um dos esquemas cognitivamente mais recorrentes. Se os modos de descrever e representar o corpo podem alimentar os modos de descrever e representar a cidade, e vice-versa, dir-se-ia também que é neste trânsito que emerge a acção ou, se quisermos, é dentro deste mecanismo de constituição mútua que as práticas e os modos de agir se tornam visíveis. Estou aqui a lembrar-me muito soltamente daquilo que nos diz Ian Hacking sobre isto: novos modos de representar e criar o real potenciam modos novos de agir (1994). Em suma, as representações são sedutoras, eficazes e, porventura, perigosas, porque estabelecem relações insuspeitas entre elas que, em última análise, fertilizam e modulam as acções humanas.

\section{Outras referências:}

BLUMENBERG, Hans, 1997, Shipwreck with Spectator: Paradigm for a Metaphor for Existence. Cambridge, Massachusetts, Londres, The MIT Press.

DENNETT, Daniel, 1995, Darwin's Dangerous Idea: Evolution and the Meanings of Life. Londres, Penguin. 
FOUCAULT, Michel, 1994 [1976], História da Sexualidade I : A Vontade de Saber. Lisboa, Relógio D’Água. HACKING, Ian, 1994, "The looping effects of human kinds", em Dan Sperber, et al. (ed.). Causal Cognition: a Multidisciplinary Approach. Oxford, Clarendon Press, pp. 351-83.

HARRINGTON, Anne, 1987, Medicine, Mind, and the Double Brain. Princeton, NJ, Princeton University Press.

Maria José Fazenda

DANÇA TEATRAL

- IDEIAS, EXPERIÊNCIAS, ACÇÕES

Oeiras, Celta, 2007, 202 páginas.

O Livro de Maria José Fazenda, Dança Teatral - Ideias, Experiências, Acções, resulta de um trabalho de investigação desenvolvido no âmbito da sua dissertação de doutoramento, o que constitui um primeiro atributo positivo desta obra. Sabemos que, muitas vezes, é com suspeita que se recebem este tipo de livros. Tal se deve, com certeza, à pouca expectativa que entre nós geram as teses de doutoramento e outras, seja porque os temas da academia - nas ciências sociais - pouca pertinência costumam ter em relação à realidade da criação e produção artísticas contemporâneas, seja pelo jargão académico, mais conforme às penumbras das salas sombrias das universidades, seja ainda pela menos-valia do seu conteúdo supostamente investigativo. Esta tese que agora aparece com o título Dança Teatral - Ideias, Experiências, Acções é a negação de tudo isto: a sua linguagem é clara e precisa, a escrita é solar e o trabalho resulta de facto de uma investigação com resultados.

Foquemo-nos um pouco mais nesta última característica para realçarmos a importância que esta obra terá para a
HOBBES, Thomas, 1981 [1651], Leviathan. Londres, Penguin.

LATOUR, Bruno, 1997 [1991], Nous n'Avons Jamais Été Modernes: Essai d'Anthropologie Symétrique. Paris, Éditions La Découverte.

\section{Luís Quintais}

Depart. ${ }^{\circ}$ de Antropologia/Univ. de Coimbra

antropologia e para a dança. Na verdade, a sua importância decorre do facto de estarmos perante uma prova, no sentido filosófico e epistemológico que o termo encerra. Citemos, a este propósito, uma obra de Fernando Gil, cujo título é Provas, e que, coincidentemente, resulta de uma lição de filosofia onde sobre a natureza da prova. Diz o filósofo que esta "comporta uma vertente objectiva (os procedimentos de facto, por exemplo os dispositivos experimentais) e uma vertente subjectiva (o grau do assentimento, 'a crença' que aqueles procedimentos são susceptíveis de provocar), a qual se desdobra em problemas próprios". ${ }^{1}$ Ora, ao confrontarmos o trabalho da Maria José Fazenda ao longo destas 202 páginas, é este guião da prova que surge como um índice substantivo. A verdade objectiva está presente no trabalho de investigação, experimentação de hipóteses e confronto com outras teses, e a vertente subjectiva está presente na crença na dança teatral como uma dança que é uma actividade, em que os principais intervenientes - bailarinos e coreógrafos - usam o corpo para estabelecer modelos de interacção (domínio das vivências sociais) e dar visibilidade a ideias,

I Cf. GIL, Fernando - Provas. Lisboa, INCM, 1986, p. 11. 
a valores e a símbolos (domínio das experiências culturais). ${ }^{2}$

Como acontece com qualquer prova, o seu enunciado final tem tendência a constituir-se em enunciado com vista à conversão pela argumentação do maior número de receptores, até atingir um auditório universal conforme as teses de Chaïm Pereleman sobre retórica e argumentação. Simultâneamente, constitui-se como um corpus cuja estabilidade o eleva à categoria de compêndio.

Dança Teatral - Ideias, Experiências, Acções estabilizará para os próximos tempos um conjunto de valores e de prerrogativas das quais eu gostaria de destacar três. A primeira é a estabilização de um conjunto de conceitos operatórios para o universo dos falantes da língua portuguesa, realizada a partir do cruzamento da antropolgia com a terminologia e com a coreografia. Com ela, podemos agora usar, sem inibição, conceitos como dança teatral, dança social, dança ritual, peça, coreografia, projecto, ballet, performance, dramaturgia, vocabulário e alguns outros mais. A estabilização epocal destes conceitos é essencial para o ensino da dança, para a coreografia e para a crítica e constitui-se como um dos grandes contributos desta obra. Um segundo aspecto que destaco é o esclarecimento sem reservas da distinção entre a dança teatral e a dança social, em que a primeira é um universo de representações culturais explícitas e de auto-reflexividade e, a segunda, a dança social, é o lugar em que as emoções, as identidades e os valores se actualizam e o sentido da comunicação e de grupo se experienciam. Para quem distingue as práticas culturais entre as que são de entretenimento e as que - supostamente - o não são, Maria José Fazenda sustenta, a meu ver, que ambas

2 Cf. FAZENDA, Maria José - Dança Teatral - Ideias, Experiências, Acções. Lisboa, Celta, 2007, p. 1. podem entreter, existindo uma inversão de hierarquia desta prioridade.

O terceiro aspecto, que decorre do privilégio de a autora conseguir reunir duas dimensões da prática de dança - foi professora de técnica de dança clássica, bailarina e crítica e é há muito antropóloga -, tem a ver com a demonstração da necessidade de recusar apenas a dimensão impressionista na recepção de um qualquer espectáculo de dança teatral, porque esta é, enquanto prática cultural, complexa, com códigos com práticas de incorporação, muito mais do que um acto de um corpo ou corpos espontâneos ou agindo naturalmente.

A análise do percurso criativo de três coreógrafos exemplificativos da dança teatral contemporânea - Merce Cunningham, Bill T. Jones e Francisco Camacho - ocupa uma parte substancial desta obra. Nela, a autora ousou sair do campo da antropolgia para o da história da dança e o dos estudos culturais, resultando numa avaliação multidisciplinar particularmente rica da explicitação das obras destes coreógrafos. Num universo de centenas de nomes passíveis de serem estudados e explicitados, a escolha destes três era um risco. Mas, exactamente por causa da abordagem multidisciplinar, o resultado é uma história de três coreógrafos de ruptura, fundamentais para se entender a relação da história da dança com a história cultural ocidental do século XX. Porque não foi por acaso, devemos enunciar brevemente os critérios que a autora escolheu para seleccionar estes três coreógrafos: por serem criadores de gerações diferentes, permitindo assim entender as rupturas, as influências, as transposições - se as havia - de linguagens e de técnicas de uns para os outros; por terem concepções diferentes da dança e dos processos criativos; e, finalmente, porque pelas suas diferenças, estes três coreógrafos permitem à autora abordagens metodológicas diversas, cada uma das quais adaptável ao objecto de estudo. 
Sumarizando o estudo de Maria José Fazenda sobre estes três coreógrafos, na leitura que deles faço, permito-me afirmar que o entendimento que fica para a história da dança é o seguinte: Merce Cunningham actualiza a democracia formal da dança, bem como as suas funções, ao desieraquizar os estatutos dos bailarinos no interior da companhia, ao descentrar os lugares de representação no palco, seguindo o preceito de Einstein de "Não há pontos fixos no espaço", ao utlizar para muitas obras a metodologia da escolha e da composição aleatória, ou decorrente da interpretação dos hexagramas Hi Ching e, finalmente, ao recorrer, de forma inovadora como metodologia, à parceria e à ligação com outras artes - música, vídeo, artes plásticas - e outros criadores, sobretudo, John Cage, Charles Atlas e Robert Rauchenberg. Na história da dança que a autora realiza nesta obra, Merce Cunnigham aparece como o clássico fundador, a rectaguarda da dança contemporânea ocidental do século XX. É justo e prova-o.

Bill T. Jones, por sua vez, aparece nesta narrativa como o coreógrafo portador da utopia social, provavelmente o último. Para estudar a obra deste criador Maria José Fazenda envereda - à boa maneira dos estudos culturais - pelo estudo da sua biografia. Uma biografia política e social, de um afro-americano portador de HIV, abordando a sua relação com os textos da literatura negra, com a história da escravatura e do movimento anti-esclavagista, sublinhando a importância da emoção e do domínio do afectivo, explícitos nas suas criações. Por último, estuda os textos de Jones, curtas narrativas, espécie de aforismos que constituem a moldura deste investimento utópico para o mundo - como ele gostaria que fosse - através da arte e, em particular, da dança. Vale, a este propósito, citar um dos mais belos e pertinentes textos alguma vez escrito por um coréografo sobre a utopia:
"Uma das coisas que agora mais me interessa é a noção de 'nós'. O que é que significa ser uma pessoa que foi rebelde, que algumas vezes também se sentiu insegura e zangada com a sociedade e que agora tenta encontrar uma forma de afirmar um 'nós' que não é sentimental, que não é fascista, mas que possa cruzar-se com aquilo que fazemos: poesia, beleza e, também tristeza. [...] Talvez seja apenas nas artes que consigo realmente encontrar a política que procuro: uma visão de poesia, mas que não é ligeira, é tenaz, forte. É a isto que me refiro quando falo do 'nós'. Quase desisti de pensar no mundo, mas agora voltei a agarrá-lo e procuro reflecti-lo tal como gostaria de o ver". ${ }^{3}$

Temos assim uma clara assunção política da arte da dança teatral, que permitiu à autora convocar para os capítulos relacionados com este coreógrafo a moldura social e artística da década de 1960, em Nova Iorque, e o trabalho pioneiro dos bailarinos, coreógrafos e artistas relacionados com a Judson Church. Desta maneira, a moldura ou, para ser antropolgicamente preciso, o contexto, permite compreender a expressão de Maria José Fazenda quando afirma que, para Bill T. Jones, “a experiência da vida é o coração da própria arte” e entendê-la na sequência de uma explicitação do percurso criador do coreógrafo, afirmação contrária a qualquer opinião sem argumentação $a$ priori.

A investigação sobre o contexto reforça-se também no caso de estudo - assim o devemos chamar - do coreógrafo português Francisco Camacho, o último coreógrafo seleccionado pela autora de entre um conjunto de coreógrafos do movimento criado no final da década de 80 , a que se convencionou chamar nova dança portuguesa. A sua escolha é justificada porque este coreógrafo representa, por um lado, aquelas que são as características deste movimento

3 Idem, p. 148. 
- ruptura com o Ballet Gulbenkian, ruptura com os modos de produção das companhias de reportório, ruptura de linguagens, ruptura de técnicas de formação - e, por outro lado, é um coreógrafo-bailarino que descontrói, de um modo mais intuitivo que programático, uma certa mitologia nacionalista personificada em figuras da história de Portugal descritas geralmente através de narrativas míticas. Para tratar e explicitar a origem da especificidade de Francisco Camacho, a diferença das diferenças, para citar Boaventura de Sousa Santos, a autora convoca todo o contexto da produção da dança em Portugal, os agentes - o ACARTE, o Expresso, o pioneirismo da Paula Massano - e a sua própria experiência como bailarina. Fá-lo utlizando duas das obras de refe-

Paulo Granjo

"TRABALHAMOS SOBRE UM BARRIL DE PÓLVORA”. HOMENS E PERIGO NA REFINARIA DE SINES

Lisboa, ICS, 2004, 329 páginas.

Correspondente à dissertação de doutoramento em Antropologia do autor (2001, ISCTE), este estudo interroga a produção de segurança em contexto de perigo industrial.

Enunciado o objectivo - "compreender de que forma resultam, do quadro de relações sociais em que estes homens trabalham, diversos mecanismos que irão limitar ou potenciar o perigo tecnológico e laboral" (p. 19) - discutem-se o percurso aí conducente, a metodologia ("observação participante", "entrevista semidirectiva” e "questionário sociológico") e os aspectos da relação do pesquisador com a problemática rência deste criador - O Rei no Exílio (1991) e Nossa Senhora das Flores (1992) -, concluindo que esta especificidade se traduz na forma de combinação e recombinação como este autor cria o património legado de acordo com as suas decisões e interesses, a sua história pessoal, a sua experiência e a especificidade do contexto em que desenvolve o seu trabalho.

E assim se conclui esta prova com mérito e com credibilidade, por força da inteligibilidade da demonstração feita. É desejável que o mesmo tipo de investigação e demonstração se faça para a dança depois destes artistas.

\section{António Pinto Ribeiro}

e com o terreno (em particular, a sua perda de acesso aos engenheiros ao revelar consistente interesse pelos operários). $\mathrm{O}$ autor ocupa-se ainda, revendo bibliografia, da "necessidade de reinventar a teoria" (p. 30) em que se encontrou, por não identificar "quadros teóricos" directamente pertinentes para o seu trabalho.

São depois brevemente apresentados o espaço físico da refinaria, os processos de fabrico e as ocupações directamente observadas: operadores de exterior (que executam, directamente sobre a maquinaria, monitorização do, e intervenções no, processo produtivo), operadores de consola (que desempenham funções similares mas de forma mediatizada, via consola electrónica, e mais abrangente, tanto na dimensão da área fabril a seu cargo, como no leque de informação de que dispõem) e chefes de turno. Analisam-se, a seguir, as "representações do trabalho" nestes grupos, por 
identificação de características-chave ("responsabilidade”, "qualificação”, "perigo”, etc.) e avaliação da sua incidência e valoração ("positiva" ou "negativa") no discurso. Estudam-se as várias fronteiras identitárias que, mobilizando espaços e máquinas, funções e qualificações, posições hierárquicas ou horários de trabalho (o autor explora, sobretudo, as implicações do trabalho a turnos), os operadores de exterior e de consola desenham e activam, consoante as circunstâncias. É dada atenção especial ao seu autoposicionamento face a algumas categorias propostas pelo autor, em particular a categoria "operário". Elementos sobre as relações de patrocinato que percorrem a fábrica e um inventário dos "perigos existentes" completam este múltiplo enquadramento.

O texto volta depois a centrar-se, principalmente, nos pensamentos e emoções dos observados, analisando a sua percepção e valorização dos perigos antes listados, a forma como concebem a ameaça que estes representam e os seus modos de a "verbalizar”. É então que o autor desenha, a partir de Luhmann, o contraste "perigo versus risco" e o situa na geografia social da fábrica: engenheiros e outros com dominância hierárquica, física e funcionalmente distantes da ameaça, ponderam o risco - que, do seu ponto de vista, é (probabilisticamente) calculável - contra ganhos (de produtividade, de rentabilidade, etc.), tendendo a "arriscar" para prossecução destes; já aqueles "que têm ou tiveram contacto directo e continuado com os perigos laborais" (p. 167) partilham uma representação de perigo contínuo e imprevisível, tendendo à prudência na sua relação com o processo produtivo.

Estabelecido este contraste, central na argumentação, é abordado um díspar conjunto de representações e práticas, quanto à sua capacidade potenciadora ou minoradora face ao perigo. Potenciam-no a "ideologia de gestão" dominante - em particular o imperativo de reduzir custos fixos de mão-de-obra e a tónica na produtividade e na rentabilidade, mesmo sob "risco" - assim como as dinâmicas de poder, formal e informal, que transpõem tais orientações para o gesto dos operadores. Já as formas e conteúdos da aprendizagem informal do ofício - que é, ao mesmo tempo, socialização no grupo ocupacional e "aculturação" nas representações partilhadas do perigo e do acidente - são considerados, juntamente com a acumulação, pelos operários, de conhecimento prático sobre o efectivo funcionamento do dispositivo técnico, factores maiores de segurança.

Perante os dados que assim constrói, o autor passa da interpretação à intervenção, advogando o reconhecimento organizacional explícito da competência e da acção dos operadores em matéria de segurança e a adopção da sua representação de perigo, na refinaria estudada como em outros "sistemas tecnológicos hipercomplexos e perigosos” (p. 266). Prevê obstáculos a uma tal diligência ("desconfiança" por parte dos trabalhadores; resistência dos dominantes, na fábrica e fora dela, perante o implícito questionamento das relações de poder vigentes), mas considera-a "necessária a uma eficaz estratégia de gestão do perigo" (p. 267), a estender à "sociedade no seu conjunto" - numa viragem "conceptual e social" em cujo âmbito a "antropologia do perigo" avança, poderá revelar-se central (pp. 278-9).

Após anexos, o volume acolhe em posfácio dois capítulos da dissertação original, que mobilizam argumentos diversos para afirmar a importância dos estudos de antropologia em meio fabril.

Desvelar o social onde a "tecnologia" parece imperar é, certamente, uma proposta aliciante. Porém, em contexto industrial, o social está também - e decisivamente - na técnica. E o gesto assume, neste olhar sobre indústria, uma presença 
surpreendentemente discreta. O autor pormenoriza o que dizem aqueles trabalhadores, mas pouco transmite sobre o que fazem: sobre os seus gestos, a corporalidade do trabalho (contudo entrevista na referência de um informante ao cheiro persistente pelo qual a fábrica irrompe na intimidade interpessoal [p. 203]), os utensílios, os processos de decisão perante a máquina. Sente-se falta de uma etnografia da técnica, dirigida ao social contido no gesto e na maquinaria - aos processos pelos quais, por exemplo, como referiu ao autor um projectista de refinarias, duas instalações idênticas na origem se tornam materialmente diferentes, após algum tempo de laboração, "sem que se saiba porquê" (p. 162). Considerando as aquisições dos estudos sobre a técnica (em antropologia, em sociologia, em história), sabe-se porquê.

Situar as relações com o perigo, e a diversidade destas na fábrica, no todo social-e-técnico das práticas de trabalho (e não especialmente no grau de proximidade aos espaços e procedimentos perigosos) ajudaria a melhor compreender o facto de, como reporta o autor, também os operários (e não apenas os engenheiros) equacionarem custos e benefícios (ainda que a sua linguagem de cálculo não seja a matemática) e, nesse equacionamento, envolverem a produção; de também os operários "arriscarem" (embora convocando não a probabilidade, mas a "sorte", ou a ideia, mais ou menos irónica, de que "paira aqui por cima a Nossa Senhora dos Petróleos" [p.167]); de os "truques" operários na condução do maquinismo (a respeito dos quais teria sido útil pormenorizar) se apresentarem ambivalentes face ao perigo.

De resto, os elementos fornecidos sobre a aprendizagem ocupacional corroboram a inserção profunda dos modos de lidar com o perigo nos modos de lidar com a técnica e com a produção: a atitude operária face ao perigo emerge no âmbito de um processo de construção, controlo e reprodução do conhecimento técnico, da qualificação e do próprio grupo ocupacional, que apresenta dinâmicas comuns a muitos contextos operários (aos quais facilmente se aplicaria o conceito de "aprendizagem situada", pese a opinião contrária dos seus próprios criadores, citados pelo autor). Por exemplo, o apertado controlo do novato, que aqui se faz sob a retórica do perigo (e sob outros idiomas noutros locais), é usual nestes contextos.

O carácter socialmente localizado dos modos de construir e reproduzir atitudes face ao perigo não deixa de sugerir um contraste interessante (que poderia ter sido explorado à volta da ideia, cara ao autor, da relação risco vs. perigo) com o individualismo que Beck associa à "sociedade do risco". O mesmo carácter torna problemática, por outro lado, a proposta de apropriação organizacional das "boas práticas" operárias, uma vez que as situa num património de conhecimento endógeno, identitário e estratégico nas relações de poder fabris - logo, reservado por inerência.

Rodeados de objectos materiais, tendemos, contudo, a render-nos ao "fetichismo da mercadoria" (Marx), escamoteando os seus contextos, materiais e simbólicos, de produção. Também por isso é esta uma leitura a ter em conta: pelo que desvela do mundo industrial, pelas portas que entreabre ao seu conhecimento e interpretação, pelo estímulo à interrogação destes processos, fascinantes e decisivos no desenhar dos “mundos contemporâneos” (Augé).

Emília Margarida Marques

CEAS/CRIA, CEEP/CRIA, bdp FCT 